\title{
Inovação, gestão e estruturação do Exército Brasileiro no Século XXI
}

\section{Innovation, management and organization of XXI Century Brazilian Army}

FLÁVIO PIETROBON-COSTA*

\section{INTRODUÇÃO}

O Estado-Nação é uma entidade representativa e amalgamadora de uma sociedade: a Nação. Se o Poder Econômico e o Poder Militar estiverem desvinculados não há segurança para o Estado-Nação. Neste caso, esses Poderes conflitarão com as necessidades de integração entre a ação econômica e a segurança alcançada por uma força militar dissuasória.

Se estes Poderes não forem integrados o desenvolvimento social, o crescimento econômico, e suas sustentabilidades, bem como a preservação ambiental, estarão em risco. A sociedade estará em risco de perda de seus recursos, de sua integridade e de seu desenvolvimento. Estará vulnerável a oponentes externos ou aventureiros internos.

Os projetos de presente e futuro da respectiva sociedade, sua visão de futuro e planejamento estratégico, fornecem o eixo da ação econômica, de sustentabilidade de seu crescimento, de preservação ambiental, desenvolvimento social, e orientam a estratégia militar.

Os crescentes desafios para os Estados Nacionais no século XXI são tão diversos quanto o número de novos atores da geopolítica internacional, como os BRICS, Organizações Não Governamentais, ONGs, e Organizações Não Estatais de Interesse Privado, ONIPs (Wilson e Stupnytska 2007; Forbes 2008). Paralelamente assistimos à redução de poder dos Estados Unidos (Galbraith 1979; Kennedy 1988; Da Silva 2008), e à acelerada ascensão de poder da República Popular da China, ou Zhongguo (Muraqiek 2005), como potencial rival dos Estados Unidos (Fairban e Goldman 2008; Gilfford 2007)

$\mathrm{O}$ atual sistema político internacional tem interesses tão dispersos e di-

* Universidade Estadual de Santa Cruz, Depto. De Ciências Exatas e Tecnológicas, Ilhéus, BA. Professor adjunto A, DSc em Modelagem Computacional, MSc em engenharia Civil. Contatos: pietrobon.costa@pq.cnpq.br, flap@uesc.br; 73 3680.5057. 
fusos quanto o crescente número de atores majoritariamente não estatais. A maior parte destes, ONGs, ONIPs, Corporações Transnacionais, não é integrante de tratados e instituições reguladoras do sistema internacional de relações, que pudessem restringir ou controlar suas ações, usualmente conflituosas com interesses dos Estados - Nação.

O conjunto das reservas brasileiras de recursos naturais deverá ser, no futuro imediato, o gerador de recursos econômicos para o País. Pode, em conseqüência, vir a desempenhar o papel de solução para o antigo dilema "manteiga x canhões", i.e., uma possível divergência entre o atendimento às necessidades civis da população e da economia, e o atendimento às necessidades de preservação ambiental e de sustentabilidade de uso de recursos naturais, bem como de incorporação de avanços tecnológicos, na forma de investimentos em equipamentos e custos de manutenção das forças armadas, exigência necessária a uma potencia em crescimento e em processo de elevação de seus compromissos externos. As próprias forças armadas, na medida em que estejam bem equipadas, sob ação de um sistema de gestão de excelência, bem treinadas e motivadas, podem assumir a segurança de reservas de recursos naturais, assegurando o uso sustentável destes recursos e a preservação de parques e reservas do patrimônio natural brasileiro.

A $2^{a}$ parte deste artigo considera uma breve avaliação de valor econômico das reservas de recursos naturais brasileiros e suas implicações para a geoestratégia brasileira no século XXI. O item 3 aborda o papel chave das inovações como incorporação de diferencial de competitividade para o Exército Brasileiro. O item 4 considera uma proposta de balanceamento entre unidades militares pesadas, leves e de resposta rápida, e a implementação de paradigmas para o Exército Brasileiro: momentum - flexibilidade - controle - mobilidade - conhecimento, na forma de uma organização plenamente quaternária de suas brigadas.

\section{PREMISSAS GEOESTRATÉGICAS, A GESTÃO DE RECURSOS NATURAIS, E PERSPECTIVAS DA DEFESA TERRESTRE}

Se na Idade Média a mensuração de riqueza, e a fonte de onde emanava poder, era a extensão de propriedade de terra (Huberman 1986), em decorrência de ser o único sistema de produção significativo, a produção em massa, característica da atualidade, demanda uma pressão significativa sobre os recursos naturais do planeta, sejam renováveis ou de magnitude finita (Busby 2007; Asici 2013; Schilling e Chiang 2011). Recursos naturais 
são fundamentais para a existência da humanidade, para a vida humana (WTO 2010). Parcela do poder dos Estados e das Organizações Trans ou Não Nacionais emana não necessariamente da posse de meios de produção ou de recursos naturais, mas de seu controle de uso e do controle dos sistemas de transporte de riquezas.

A evolução da produção não relegou a um segundo plano a sociedade industrial, como esta tornou defasado e superado o feudalismo (Aquino 2003), mas sim a integrou em uma complexa sociedade de conhecimento, o que requer o aperfeiçoamento não só de processos e mecanismos de produção e sua otimização (Slack et al 2008), mas a reestruturação das organizações de aperfeiçoamento de seus sistemas de gestão, sobretudo da nova forma de riqueza: o conhecimento e a inovação (Moreira e Queiroz 2007).

\subsection{Implicações geoestratégicas de escassez de recursos ambientais}

No século XXI o controle de recursos naturais será foco de conflitos, apresentando-se o controle de escassas reservas como um forte atrativo de elevada lucratividade (Nordas e Gleditsch 2007). É previsível o esgotamento de jazidas minerais ao longo deste século, a proximamente futura escassez de água fresca potável, e a elevação de necessidades por recursos das florestas tropicais.

A carência ou escassez de recursos naturais vitais irá elevar a intensidade de tensões sociais e riscos por conflitos (Pietrobon-Costa 2011a; Barnett 2000; Raleigh e Urdal 2007). Será um estímulo ao seu tratamento como commodities de alta lucratividade; e potencial fonte de conflitos entre Estados nacionais, e entre estes e as Organizações Transnacionais, sejam estas corporações ou grupos não regulares. Os ganhos potenciais, pelo menos financeiros, originados daquelas reservas de recursos pode ser um forte atrativo para intervenções externas sobre o Brasil e objeto de ações contrárias aos interesses nacionais, pelos novos atores do difuso panorama internacional do século XXI (Busby 2007; Reilly 2012). Para dissuadir tais ações um Exército Brasileiro forte é necessário. Essa necessidade se confunde com a de perpetuação do Brasil como Estado-Nação. As ações da força terrestre nacional, no século XXI, convergem para a integração da salvaguarda dos interesses e dos recursos naturais nacionais (de Souza 2007).

O Brasil é detentor de $98 \%$ das reservas mundiais de nióbio e único 
exportador global (Silva 2001). As reservas alcançam valor de US $\$ 100.0$ bilhões, em valores de 2010 (Pietrobon-Costa 2011a e 2011b), podendo chegar rapidamente a US\$ 2.9 trilhões, em um processo de valorização semelhante à do petróleo. A água potável é um mercado superior a US\$ 400.0 bilhões/ano, nos próximos anos, dada a escassez de abastecimento já presente, por exemplo, na China e na Índia, conectando diretamente escassez, empobrecimento e crise sócio-ambiental (Ohlsson 2000). Quanto às reservas de produtos florestais, a preservação da floresta em pé, da Amazônia Brasileira, pode gerar recursos da ordem de US $\$ 130.0$ trilhões anuais para o Brasil; somente em produtos base para medicamentos o valor é equivalente a US $\$ 1.73$ trilhão (Pietrobon-Costa $2011 \mathrm{a}$; Barlow et al. 2007). O pré-sal brasileiro tem reservas estimadas em 12 a 14 bilhões de barris, valendo de US $\$ 1.39$ a US $\$ 1.62$ trilhões, na cotação de abril de 2011.

Considerado o papel estratégico destas fontes de recursos, o controle sobre recursos naturais assegura a sustentabilidade da atividade econômica, a preservação ambiental, e seu uso sustentável. Quanto à Amzônia, o seu controle e de seus recursos florestais é garantia de sua preservação. Identicamente, o controle sobre as demais reservas de recursos biogenéticos, naturais, de água doce e jazidas minerais é fundamental para o desenvolvimento social, científico-tecnológico e econômico do Brasil.

A atual riqueza brasileira desses recursos, e a perspectiva de poder econômico daí derivada, não fecham a equação de Balanço de Poder Nacional, BPN. Considerando as manifestações de poder de um Estado-Nação como sendo segmentadas em: econômico, psicossocial, político, militar, científico - tecnológico, e territorial - natural, a segurança do território nacional, e a simples guarda e preservação da exploração sustentável daqueles recursos, por si só não assegura poder ao Brasil. A capacidade do país em realizar suas perspectivas nacionais e alcançar seus objetivos, à luz do BNP, requer que estejam esses segmentos fortalecidos, equilibrados entre si, e capazes de serem expressos. Manifestar livremente suas aspirações é Poder. Então é necessário ao Brasil fortalecer esses cinco segmentos de poder para que seu Poder seja fortalecido.

Atualmente, e pelas próximas décadas no futuro, o poder econômico-financeiro internacional, bem como reivindicações político-sociais, está e estará pulverizado: (a) entre Estados-Nação, e (b) entre Corporações Transnacionais Bancárias, Financeiras, ou de Investimentos, além de (c) Organizações Transnacionais Não Estatais: Organizações Não Governa- 
mentais, ONGs, usualmente com interesses próprios, e Organizações Não Estatais Paramilitares, ONEPs, com interesses paraestatais. Dessas organizações pode, e provavelmente, se originarão ações sobre os recursos naturais brasileiros.

A preservação de estabilidade social, desenvolvimento econômico, e riqueza natural do Brasil sobre controle dos brasileiros dependem de $\left(1^{\circ}\right)$ uma política econômica e de desenvolvimento sustentável, e $\left(2^{\circ}\right)$ de uma política nacional de defesa e de uma força militar de dissuasão (Pietrobon-Costa 2011b).

\subsection{Missões da Força Terrestre no século XXI}

A defesa de recursos naturais considera a sua preservação, o controle de acessos, segurança de uso renovável, e de renovação.

As reservas daqueles recursos encontram-se razoavelmente distribuídas em todo o território brasileiro, continental e costeiro, exigem defesa das vias de acesso e transporte-distribuição para os centros urbanos, as usinas de processamento e beneficiamento, e para centros industriais e urbanos, bem como núcleos de produção de energia, e sistemas e terminais de transporte. Tais premissas demandam atenção e previsão de ação de Grandes Unidades militares, GUs, de valor brigada, para defesa, dissuasão, e ações específicas.

Quanto à geração de energia, com grandes centrais de produção e recursos energéticos razoavelmente distribuídos no território nacional, a existência de GUs de operações especiais viabiliza ação rápida de defesa e segurança.

Na Área Operacional do Continente, AOC, o próprio território nacional, o projeto de uma Força Militar Terrestre precisa considerar como condicionantes os aspectos biofísicos, quanto à cobertura vegetal, topografia e extensões de terrenos de características específicas, além da malha fluvial e distribuição de planícies e planaltos. Grandes unidades especializadas a ações em biomas de características específicas são necessárias: GUs de selva, pantaneiras, de montanha, e de caatinga.

Fatores que induzem o projeto de GUs de manobra para a Força Terrestre, as diversas regiões do Brasil contemplam ações de unidades militares terrestres em uma diversidade grande de biomas, topografias e eixos geofísicos de manobra (Pietrobon-Costa 2011 a e 2011 b).

$\mathrm{O}$ conjunto desses condicionantes implica a diversidade de missões para 
o Exército Brasileiro no atual século.

Nas próximas décadas, o Brasil estará frente a frente com a necessidade de dispor de recursos militares para: (a) a defesa da integridade territorial (guarda de fronteiras, interdição de acessos a oponentes, manobra e ações de combate); (b) a segurança de fontes de recursos naturais: renováveis e não renováveis, garantia de acesso e de segurança de vias de transporte destes recursos e de sua produção econômica, a guarda e defesa de parques e unidades de conservação de biosistemas naturais; (c) a defesa de centros nacionais de produção, e da disponibilização de insumos e recursos para que esta produção se conclua com sucesso; (d) a garantia da lei e da ordem, participação ou liderança de missões de paz internacionais, e suporte militar à autoridade civil; bem como (e) o combate intensivo e tecnológico, segurança contra ações de atores militarizados não estatais, Organizações Transnacionais contra os interesses nacionais, e combate a grupos armados não estatais, sejam de origem empresarial, sejam grupos armados terroristas, clandestinos ou guerrilheiros que usem o território nacional como base de apoio.

\subsection{Diversidade e dispersão de tipos de unidades}

A execução dessas missões pode ser efetuada por ações de destacamentos, pequenas ou subunidades (SUs) de armas combinadas em ambientes urbanos, combinadas com a manobra e ações de combate de grandes unidades (GUs) em vastas áreas, entre as metrópoles, e em grandes distâncias.

Tal abordagem requer a construção de forças flexíveis e versáteis, em parte em alerta imediato, apresentando rapidez de resposta às demandas que se apresentem. Amplamente capazes de variadas ações especiais, específicas dos diversos biomas brasileiros, e capacitadas a operações convencionais, de guerrilha, ou não lineares.

O requisito estratégico da Força Terrestre é por integração de grandes unidades (valor brigada), com elevado poder de combate, pesadas e leves, com as GUs de operações em áreas específicas, e as especiais e estratégicas. Às unidades de alta velocidade de deslocamento, mecanizadas e leves, é necessário agregar unidades pesadas, i.é., blindadas que, com as mecanizadas, apresentem elevado poder de fogo e de choque contra oponentes. Com estes tipos de GUs é necessário integrar GUs de operações rápidas e especiais.

O poder de fogo e choque das GUs pesadas de carros de combate e 
blindadas e a rapidez de resposta e de poder de fogo das GUs mecanizadas compõem o momentum, juntamente com a integração de operações nos TOs com as unidades de resposta rápida e as leves (Pinto Silva 2009).

O Exército Brasileiro se depara então, a contar de agora e pelas próximas décadas, com a necessidade de dispor de um leque de unidades especializadas a diversas ações complementares e integradas, dispostas geograficamente em sub-regiões específicas de todo o território nacional, disponíveis em caráter imediato a ações em suas áreas de responsabilidade, inicialmente, e em todo a AOC, se necessário.

A dispersão de meios e de sistemas de apoio às Organizações Militares, particularmente às GUs, impõe a descentralização como eixo estruturante.

\section{INOVAÇÃO COMO EIXO DE APERFEIÇOAMENTO}

A estruturação de uma Força Terrestre apta à dissuasão crível e ao atendimento de suas missões, de forma econômica e operacionalmente eficiente, é realizável pela incorporação de inovações e de alta tecnologia aos seus sistemas e procedimentos operacionais.

A incorporação de inovações aos produtos e processos, bem como procedimentos de gestão e serviços, em todas as instituições sociais e econômicas humanas, seja pelas corporações e empresas, bem como instituições de ciência e tecnologia, tem sido o diferencial que determina o fortalecimento ou perpetuação da instituição. É determinante à consecução dos objetivos, missão e visão de futuro da instituição. Não é diferente para uma força militar.

A inovação é a introdução de novidades no sistema de geração de objetivos, ou seja, na produção fim da organização, obtida pela pesquisa, desenvolvimento, assimilação na novidade, e exploração do sucesso (Moreira e Queiroz 2007) advindo do emprego de novos equipamentos, sistemas, produtos, processos e arranjos sociais. A inovação introduz uma vantagem competitiva na organização, em comparação com seus concorrentes, i.é., os oponentes que lhe oferecem risco. Assimilar o novo na forma de inovação oferece solução diferenciada e em posição à frente do oponente, tornando possível satisfazer as necessidades da sociedade e dos indivíduos.

A Força Terrestre Brasileira só tem a ser beneficiada, e em conseqüência, a sociedade civil, com a introdução de inovações na forma de novas tecnologias ou aperfeiçoamentos em equipamentos e sistemas operacionais - inovações tecnológicas ou de produtos -, ou na forma de aperfeiçoamentos 
organizativos e de gestão - inovações organizacionais e de processos -, ou na forma de introdução de avanços em suas missões, visão de futuro, e mecanismos de relacionamento entre o corpo de tropa e deste com a sociedade civil - inovações sociais -. Porém, a introdução de inovações exige a flexibilidade e a abertura dos gestores para a análise, planejamento e absorção destas inovações.

A inovação é, para as empresas e corporações transnacionais, o diferencial que permite melhores resultados no mercado frente aos concorrentes. De forma análoga para as forças armadas, e em particular para o Exército, a inovação é o diferencial que permite alcançar o sucesso em suas missões e ações, i.é., a vitória com menor perda de recursos, maior segurança aos militares, e em menor intervalo de tempo, sobre eventuais forças militarizadas de Organizações Transnacionais bem como de organizações não estatais, contra forças armadas de Estados Oponentes, ou em conflitos com outros inimigos nacionais que possam se apresentar no futuro.

\section{PARADIGMAS DE MODELAGEM OPERACIONAL DO EXÉRCITO BRASILEIRO: UMA ESTRUTURA QUATERNÁRIA E INOVADORA PARA AS GUS, E A DUALIDADE FORÇA - LEVEZA}

A vitória é assegurada ao general que conhece a si mesmo e ao oponente (Sun Tzu e en McNeilley 2002), ao mais hábil na modelagem do inimigo, na manobra e na rapidez de resposta aos desafios. Tais paradigmas compõem o pentagrama: momentum - flexibilidade - controle - mobilidade conhecimento, que orienta a modelagem do EB para o futuro imediato e as décadas seguintes no século presente.

A Estratégia Nacional de Defesa, END (Dec. 6.702 2008), estabelece a incorporação de inovações como eixo das oportunidades a serem exploradas no processo de estabelecimento de uma política de defesa nacional, e no fortalecimento operacional das forças armadas brasileiras. A absorção de inovações, e os aperfeiçoamentos resultantes das consequentes alterações na cultura institucional são determinantes no sucesso das ações pela Força Terrestre. A END pontua ainda a mobilidade e a flexibilidade, elementos determinantes e condicionantes da nova estruturação do Exército Brasileiro.

Quanto à mobilidade e flexibilidade como elementos chave da evolução do EB, a END postula em linhas gerais o que já está posto no Manual IP100-1 (EB 1996). 
Precisam ser considerados novos eixos de possíveis avanços de forças ameaçadoras à paz, integridade territorial e preservação dos recursos nacionais. As Amazônias, Verde e Azul, são prioridades. São também prioritárias as fronteiras terrestres, como ambiente de monitoramento, vigilância e primeira linha de defesa contra possíveis oponentes.

Sendo inviável guarnecer todo o litoral, as faixas de fronteira terrestre, e as diversas regiões interiores do território nacional, a mobilidade estratégica é imperativa. É necessário considerar para o EB o princípio de capacidade de se fazer presente, e não ser onipresente, nas áreas a serem guarnecidas, i. é., nas frentes ou eixos de avanço de oponentes sobre os sistemas de produção econômica, de geração de energia, de ocupação demográfica, e de reserva ou uso de recursos naturais.

Considerada a presença de Subunidades, SUs, de alerta e vigilância, nas fronteiras, e de Grandes Unidades de Combate, GUs, de valor brigada, altamente móveis e dotadas de capacidade de mobilidade estratégica, conforme postulado na END, é possível efetivar a capacidade de se fazer presente quando necessário. Isso inclui a manobra operacional rápida como seu eixo de ação; o que só é alcançavel por via aérea.

A criação de Brigadas de Infantaria Mecanizada, Bda Inf Mec, no EB tem sido uma busca de integração dos princípios de mobilidade, flexibilidade, e poder de fogo nos diversos projetos propostos das Bda Inf Mec. Todos unânimes quanto à adoção de uma estrutura quaternária bem como na elevação do poder de fogo da artilharia, porém buscando elevar o quantitativo de carros de combate (Peres e Souza 2007), adotando um maior quantitativo de infantaria em presença de carros de combate sobre rodas, bem como de cavalaria mecanizada (Mesquita 2010), ou propondo a total supressão de carro de combate destas brigadas, como mecanismo de elevação de sua velocidade de manobra global, porém inserindo SU de inteligência, operações especiais e guerra eletrônica, elevando a capacidade de prontidão e resposta em combate (Morgadom et al. 2008).

Aqui é proposto solucionar tal equação, considerando idéias destas pesquisas, e buscando incoporar inovações para lidar com aspectos de prováveis operações futuras. É buscado reestruturar as Brigadas do EB segundo um novo entrelaçamento e relacionamento organizacional de SUs, em torno da incorporação de inovação tecnológica e organizacional às GUs; disponibilizando aos comandantes e seus assessores a capacidade de exercício de atribuições segundo os cinco princípios daquele pentagrama.

É considerada a integração de momentum e mobilidade, fortalecimento 
de seu sistema de C4I e suporte, realizando GUs quaternárias flexíveis, versáteis, e inter-operacionais (Pietrobon-Costa 2011a) na forma de brigadas modulares. Este processo complementa e aperfeiçoa a decisão de inovar em equipamentos. No seu conjunto estas inovações geram aperfeiçoamento na doutrina e na estratégia de emprego.

O Manual IP-100-1 (EB 1996) descreve as bases para a modernização operacional do Exército Brasileiro. No futuro próximo os comandantes das GUs enfrentarão um ambiente operacional extremamente fluido, rapidamente mutável, e multidimensional, exigindo alto grau de iniciativa e exercício autônomo de liderança, rapidez na resposta a desafios, agilidade, sincronização de ações e de movimentação de subunidades integrantes das respectivas GUs, e elevada capacidade de gerenciamento de informações e ações no ciberespaço, i.e., guerra eletrônica, comunicações, e aquisição/ estruturação de dados gerando conhecimento do TO.

As atuais e futuras operações militares são predominantemente não lineares, contínuas, utilizando fortemente a $3^{\mathrm{a}}$ e $4^{\mathrm{a}}$ dimensões: a ação verticalizada - aeromóvel e aerotática -, e a utilização do espectro eletromagnético, além da $5^{\mathrm{a}}$, o apoio da sociedade civil.

As manobras desbordantes ou envolventes serão predominantes, impactando a retaguarda do inimigo, isolando-o, impedindo sua manobra, utilizando meios de mobilidade em ambientes naturais, e atingindo os objetivos estratégicos (Martins 2008), agregando poder de fogo não só quantitativamente, mas pela integração e interoperacionalidade de SUs das Brigadas, e otimização de seu emprego operacional e tático (USA Army 2012), bem como pela interdependência e gestão otimizada de recursos humanos, equipamentos e incorporação de inovações (EB 2010).

A presente proposta considera que as ações das Brigadas serão em áreas (ou volumes) multidimensionais, e não em frentes lineares. O máximo poder de combate deve ser aplicado, no local e momento oportuno, visando à obtenção da vitória o mais rápido possível.

A organização e gestão das forças integradas das SUs considera as características do terreno e do ambiente, conquistando e mantendo a iniciativa e a rapidez das operações, explorando os pontos fracos do inimigo, conservando o espírito ofensivo e a manutenção da própria liberdade de ação. Esse procedimento de operação exige dos comandantes de GUs e SUs a tomada de decisões independentemente de ligações com seu escalão superior, apoiados por uma combinação de subunidades em cada GU capaz de permitir a manutenção da mobilidade, versatilidade e momentum, 
respondendo de forma flexível às rápidas mudanças demandadas no TO, nas várias dimensões de combate.

A fig. 1 apresenta tal estrutura inovadora, quaternária para brigadas modulares, exemplificada para a Brigada de Infantaria Mecanizada, sendo esta GU de manobra em velocidade elevada, na maior parte levemente blindada, de combate aproximado de infantaria, por envolvimento a pé ou embarcada, utilizando o fogo de suas próprias viaturas mecanizadas, e o apoio de blindados mecanizados e sobre lagartas, de combate e manobra terrestre, dotada de capacidade de manobra vertical. As abreviações seguem as convenções usuais (MD-33-M-02 2008).

A reestruturação é fundamentada na composição de cada GU segundo gestão de atribuições e funções, diretamente controladas do estado-maior geral da GU: Módulo de Comando e C4I (Coordenação, comando, controle, comunicações, e informações), Módulo de Choque e Manobra, Módulo de Fortalecimento de Manobra e Apoio de Fogo, e Módulo de Apoio e Suporte de Combate.

O Módulo de Controle incorpora meios de operação em ciberguerra, na $4^{\mathrm{a}}$ dimensão, i.é., no espectro eletromagnético, e de simulação e engodo do comando e controle oponente, por meio de guerra furtiva e operações psicológicas, e SU de reconhecimento e precursores. Tal composição disponibiliza meios concentrados e especializados de monitoramento, aquisição e processamento de dados, geração de informações, sondagens e esclarecimento de dispositivos, organização e posições de comando e do suporte de combate de oponente, e de mapeamento de vias e corredores de mobilidade inimigos.

A dotação de quatro subunidades valor batalhão ou regimento, de acordo com o critério de armas combinadas, no Módulo de Choque e Manobra viabiliza a ação da GU em três áreas de operação, ou frentes, simultaneamente, com a manutenção de uma destas subunidades em reserva de pronto emprego, ou a formação de grupos de batalha, ou forças-tarefas flexíveis e de elevada manobrabilidade, aptos a atuar em cenários fluidos e rapidamente mutáveis, conforme a evolução do panorama tático, dotando a GU de capacidade de ação reforçada simultânea em várias frentes ou áreas, com apoio tático mútuo.

No Módulo de Fortalecimento da Manobra e de Apoio de Fogo, a presença de um Esquadrão (Esq.) de Cavalaria Blindada (ou de Choque) e de uma Companhia (Com.) de Infantaria Leve (aeromóvel) fornece capacidade de ações de ruptura e batalha, em movimento rápido, com proteção fortemente blindada (Mitcham Jr. 2000), e de ações de envolvimento vertical por via aérea. O Esquadrão (Esq.) de Aviação habilita a operação aérea tridimensional: ataque tático, a escolta, reconhecimento, ligação e a patrulha, e transporte ou assalto aeromóvel. Este Módulo integraliza inter-operacionalidade e ver- 
Figura 1 - GU de manobra rápida, levemente blindada, de manobra de infantaria

\begin{tabular}{|c|c|}
\hline GU & Bda Inf Mec \\
\hline \multicolumn{2}{|l|}{ Módulo (ou serviço) } \\
\hline Comando e C4l & $\begin{array}{l}\text { Cia de Comando e C4I } \\
\text { Cia de Segurança Interna } \\
\text { Cia IGEOps } \\
\text { Cia de Comunicações } \\
\text { Cia de Precursores e Reconhecimento }\end{array}$ \\
\hline Choque e manobra & $\begin{array}{l}1^{\circ} \mathrm{B}+\mathrm{l} \text { de Infantaria Mecanizada } \\
2^{\circ} \mathrm{B}+\mathrm{l} \text { de Infantaria Mecanizada } \\
3^{\circ} \mathrm{Btl} \text { de Infantaria Mecanizada } \\
\text { Rgt de Cavalaria Mecanizada }\end{array}$ \\
\hline $\begin{array}{l}\text { Fortalecimento de manobra } \\
\text { e apoio de fogo }\end{array}$ & $\begin{array}{l}\text { Esa de Cavalaria Blindada } \\
\text { Cia de Infantaria Leve (Aeromóvel) } \\
\text { Esqd de Aviação de Emprego Geral } \\
\text { G de Artilharia de Campanha } \\
\text { Bia de Artilharia Anti-aéreo }\end{array}$ \\
\hline Apoio e suporte de combate & $\begin{array}{l}\text { Btl de Engenharia } \\
\text { Btl de Apoio Logístico } \\
\text { Cia de Saúde } \\
\text { Pel de Guerra NBQ }\end{array}$ \\
\hline
\end{tabular}

satilidade orgânica às GUs. Nas GUs "pesadas” as SUs componentes desta Módulo atuam ágeis e velozes em manobra, desbordamento e envolvimento, sendo elementos de cobertura, segurança ou reforço da região, ou eixo, principal de ação. Em GUs "leves”, neste Módulo, estão SUs dotadas de capacidade de choque, poder de fogo, e manobra sob proteção blindada, sendo componentes de batalha, criação de oportunidades e ruptura de dispositivos oponentes.

A presença de SUs características da missão fim da GU em que estão integradas, no Módulo de Choque e Manobra, juntamente com SUs disponíveis no Módulo de Apoio de Fogo e Manobra, pesadas se a GU for leve ou de emprego rápido ou em ambiente especializado, e leves se a GU respectiva for blindada, de choque ou batalha, pesada, fornece meios de ação rápida e flexível, e habilita o comando da GU a prover operações continuamente, em função da alteração de conhecimento sobre o oponente e suas disposições táticas e operacionais.

A fragilidade e impotência dos organismos internacionais para impedir conflitos fomentados por interesses de grupos ou países poderosos (Pinto Silva, 2008), no Sistema Internacional de Estados, Corporações e Organizações Transnacionais, como no caso da $2^{\text {a }}$ Guerra do Golfo, no Iraque, ou nos conflitos por recursos naturais desde o final do séc. XX, é por si só motivação para o desenvolvimento de uma força nacional militar de dissuasão poderosa, em que se insere o Exército Brasileiro, em que esta proposta de reestruturação de Brigadas permite a adequada flexibilidade, mobilidade, momentum e conhecimento de si e do oponente para enfrentar os novos desafios militares que se apresentam. 


\section{CONCLUSÃO}

A segurança de todo Estado-Nação depende do vínculo entre o Poder Econômico e o Poder Militar. A segurança, interna e externa, exige que a sociedade invista parte de seu resultado produtivo em inovadores sistemas de armas e no aperfeiçoamento da gestão de seu sistema de dissuasão.

A história é repleta de casos de Estados, Países ou Estados-Nação que desprezaram a evolução tecnológica e/ou que engessaram o seu desenvolvimento econômico, comprometendo sua capacidade de se opor à ação militar de interesses não nacionais, incorrendo em prejuízos à sua Sociedade. $\mathrm{O}$ desenvolvimento, e a sua sustentabilidade, são intrinsecamente dependentes da segurança: externa e interna.

Em um panorama futuro de escassez de recursos naturais, a busca por novas fontes e fornecedores confiáveis será um motivador de conflitos por recursos naturais. Os principais alvos serão reservas de recursos naturais, principalmente água doce, recursos minerais, florestais, e biogenéticos, dos quais o Brasil é grande possuidor. $\mathrm{O}$ difuso atual e futuro panorama de relações internacionais, repleto de novos atores transnacionais, organizados em torno de interesses de origem econômica, de origens nacionais difusas, é motivo de preocupação. Ações movidas por perspectiva de lucros vultosos ou por atividades econômicas escusas são uma ameaça para o Brasil no futuro próximo.

A incorporação de inovações tecnológicas, organizacionais, e de gestão, bem como sociais, deverá ser o diferencial a colocar o Exército Brasileiro à frente de possíveis oponentes futuros, assegurando uma capacidade dissuasória efetiva e forte, demandando reestruturação segundo forças flexíveis e versáteis, simultaneamente pesadas e leves no sentido da força e velocidade de emprego. As GUs devem ser capazes de deslocamento estratégico rápido, necessariamente por vetores aéreos (Jamison et al. 2005), assegurado pelo emprego de novas tecnologias. Unidades autônomas, plenamente interoperacionais, habilitadas a se contrapor aos desafios que se delineiam para este século.

Essa estrutura apresenta, incorporando momentum, flexibilidade e mobilidade em $3^{\mathrm{a}}$ e $4^{\mathrm{a}}$ dimensões operacionais à GU brigada, e a possibilidade de desenvolvimento de operações na $5^{\mathrm{a}}$ dimensão: ações psicológicas e interações com a sociedade civil. Fornecem meios de gestão, comando e independência de ação a essas unidades.

Parafraseando Guderian (1999), novas armas chamam por novos meios de combater, pela apropriada forma de organização, e por táticas apropriadas. 


\section{INOVAÇÃO, GESTÃO E ESTRUTURAÇÃO DO EXÉRCITO BRASILEIRO NO SÉCULO XXI}

\section{RESUMO}

As futuras escassas reservas de recursos naturais serão fator de ação de atores não estatais por lucratividade e satisfação de suas necessidades de produção econômica. A opção por ações armadas será por seu controle. Inovações incorporadas ao Exército fomentarão seu sucesso em defender o Brasil de tais ações.

Palavras-chave: Exército Brasileiro. Conflitos por recursos naturais e ambientais. Dissuasão estratégica. Inovação organizacional e tecnológica.

\section{ABSTRACT}

The future scarcity of natural resources reserves will be a factor of action by non-state actors motivated by profitability and economic production demands. Armed action will be an option, motivated by the intent to control them. Innovations, incorporated to the Brazilian Army, are a promotion of success to defend Brazil from those actions.

Keywords: Brazilian Army. Conflicts for environmental and natural resources. Strategic deterrence. Technological and organizational innovation.

\section{REFERÊNCIAS}

Aquino, R. S. L., Franco, D.A., Lopes, O. G. P.C. 2003. História da Sociedades. Vol 1, Vol. 2. LTC Editora.

Asici, A. A. 2013. Economic growth and its impact on environment: A panel data analysis. Ecological Indicators. pp. 324-333.

Barnett, J. 200. Destabilizing the environment-conflict thesis. Vol. 26. Review of International Studies. p. 271-288.

Busby, J. W. 2007. Climate change and national security: an agenda for action - CFR Technical report. No. 32. Council of Foreign Relations.

Couto e Silva, G. 1981. Conjuntura política nacional; O Poder Executivo \& Geopolítica do Brasil. Editora UnB. 
Da Silva, F.C.T. 2008. O Futuro dos Estados Unidos e a Teoria dos Três Mundos. Tempo Presente.

De Souza, C. B.C. 2007. A crescente importância geopolítica da Amazônia no contexto mundial: uma proposta de preservação dos interesses nacionais. Monografia. Escola de Guerra Naval.

Exército Brasileiro. 1996. Bases para a modernização da doutrina de emprego das forças terrestres - Doutrina Delta - IP 100-1. Estado-Maior de Exército.

Exército Brasileiro. 2010. O processo de transformação do Exército - 2015 a 2035. Estado-Maior de Exército.

Fairban, J.K., Goldman, M. 2008. China, uma nova história. L\&PM.

Forbes. 2008. The Global 2000: the biggest companies in the world. Forbes magazine.

Galbraith, J.K. 1979. A era da incerteza. UnB.

Gilfford, R. 2007. China road, a journey into the future of a rising power. Random House Editions.

Guderian, H. 1999. Achtung-Panzer! The development of tank warfare. Cassel Military Paperback.

Hubberman, L. 1986. A história da riqueza do homem. $21^{\text {a }}$ ed. LTC.

Kennedy, P. 1988. Ascensão e queda das grandes potências. Editora Campus.

Jamison, L., Sommer, G. S., Porche III, I. R. 2005. High-altitude airships for the future force army. In: Technical report. Vol. 234. Rand Corporation.

Martins, C. B. 2008. A brigada de infantaria mecanizada na operação de transposição de curso de água. Monografia. ECEME.

McNeilley, M. 2002. Sun Tzu e a arte da guerra moderna. Editora Record.

Mesquita, A. A. 2010. Idéias sobre a infantaria mecanizada. In: Ação de Choque. 10: 3-7.

Mitcham JR., S. W. 2000. The Panzer Legions. Stackpole Books.

Moreira, D. A., e Queiroz, A. C. S. 2007. Inovação organizacional e tecnológica. Pioneira Thompson Learning Ltda. 
Morgado, F. R. B., Gomes, M. G., F. M., e Barcellos Neto, F. 2008. As forças mecanizadas do Exército Brasileiro: uma proposta de modificação, atualização e modernização. UFJF: Centro de Pesquisas Estratégicas Paulino Soares de Souza. Murawiec, L. 2005. China's grand strategy is to make war while avoiding a battle. Armed Forces Journal. November 2005.

Nordas, R., Gleditsch, N.P. 2007. Climate change and conflict. Vol. 26. Political Geography. p. 627-638.

Ohlsson, L. 2000. Water Conflicts and Social Resource Scarcity. In: Phys. Chem. Earth (B). 25 (3): 213-220.

Pereira, C. P. F. 2007. Geopolítica e o futuro do Brasil. Bibliex.

Peres, S. S. L., Souza, S.V. 2007. A brigada de infantaria mecanizada: uma proposta de organização e de emprego em operações de defesa de área. Monografia. ECEME.

Pietrobon-Costa, F., Silva, N. S., Machado, R. F. O. 2007. Por uma ampliação da abordagem científica do conceito de ecossistemas. Boletim Interfaces da Psicologia. 1: $1-12$.

Pietrobon-Costa, Flávio. 2011a. Um modelo de força para o Exército Brasileiro no Século XXI: ação geopolítica e geoestratégica. A Defesa Nacional. 817 (2): 4-19.

Pietrobon-Costa, Flávio. 2011b. Paradigmas de modelagem da Força Terrestre Brasileira para enfrentar os desafios geopolíticos do Século XXI. Carta Internacional. 5 (1).

Pinto Silva, C.A. 2009. A infantaria leve do exército brasileiro. Revista do Exército Brasileiro. 146 (3): 3-7.

Pinto Silva, C.A. 2008. Repensando a operacionalidade da Força Terrestre Cenários. A Defesa Nacional. 811 (2): 70-73.

Presidência da República. 2008. Estratégia Nacional de Defesa. Decreto 6.703.

Proença Jr., D., Duarte, E.E. 2003. Projeção de poder e intervenção militar pelos Estados Unidos da América. Revista Brasileira de Política Internacional. 46 (1): 134152 .

Raleigh, C., Urdal, H. 2007. Climate change, environmental degradation and armed conflict. Vol. 26. Political Geography. 26: 674-694.

Reilly, J. 2012. Green growth and the efficient use of natural resources, Massachucets Institute of Technology. Technical report no. 221. MIT editions. 
Schilling, M., Chiang, L. 2011. The effect of natural resources on a sustainable development policy: The approach of non-sustainable externalities. Energy Policy. February 2011.39 (2): 990-998.

Slack, N., Chambers, S., and Johnston, R. 2008. Administração da produção. Editora Atlas.

U.S.A. Army. 2011. Army modernization plan 2012. Department of the army G-8.

World Trade Organization. 2010. World Trade Report-2010. WTO.

Recebido em: 23/04/2013. Aprovado em: 10/07/2013. 